\title{
Iron chelation therapy in the myelodysplastic syndromes and aplastic anemia: a review of experience in South Korea
}

\author{
Jong Wook Lee
}

Received: 28 April 2008/Accepted: 2 June 2008/Published online: 5 July 2008

(C) The Japanese Society of Hematology 2008

\begin{abstract}
Emerging clinical data indicate that transfusion-dependent patients with bone marrow-failure syndromes (BMFS) are at risk of the consequences of iron overload, including progressive damage to hepatic, endocrine, and cardiac organs. Despite the availability of deferoxamine (DFO) in Korea since 1998, data from patients with myelodysplastic syndromes, aplastic anemia, and other BMFS show significant iron overload and damage to the heart and liver. The recent introduction of deferasirox, a once-daily, oral iron chelator, may improve the availability of iron chelation therapy to iron-overloaded patients, and improve compliance in patients who may otherwise find adherence to the DFO regimen difficult.
\end{abstract}

Keywords Aplastic anemia $\cdot$ Myelodysplastic syndromes · Iron overload · Deferasirox

\section{Introduction}

Bone-marrow-failure syndromes (BMFS) are a group of hematopoietic stem cell disorders that can involve the erythroid, myeloid, and/or megakaryocytic cell lines. These conditions can arise from a genetic condition, or result spontaneously from disease or damage to the hematopoietic stem cells. The inherited BMFS include aplastic anemia (AA), Fanconi's anemia, dyskeratosis congenita, and Diamond-Blackfan anemia (DBA), along with other

J. W. Lee $(\square)$

Division of Hematology, Department of Internal Medicine,

St. Mary's Hospital, College of Medicine,

The Catholic University of Korea,

Seoul, Korea

e-mail: jwlee@catholic.ac.kr disorders. AA is also the most common cause of acquired bone marrow failure [1]. In most cases of myelodysplastic syndromes (MDS) the cause is unknown, although some cases can be linked to hematopoietic injury resulting from previous exposure to genotoxic factors such as chemotherapy, radiation, and pesticides [2].

The incidence of AA is higher in Asian countries than it is in Western countries; in Europe and the US, the ageadjusted incidence is 2.2 per million per year, compared with 11.0 per million per year in Japan and Korea [3]. According to a recent epidemiological survey, the incidence of AA in Korean children is 4.5 per million per year, with $4.1 \%$ occurring as congenital AA [4]. A recent retrospective analysis of 50 Korean patients with MDS showed that the most common MDS subtype was refractory anemia (RA; in $36 \%$ of patients), while the incidence of the other subgroups were $24 \%$ for RA with excess blasts (RAEB), $24 \%$ for RAEB in transformation, $12 \%$ for RA with ringed sideroblasts and $2 \%$ for chronic myelomonocytic leukemia. The median survival of the low-, intermediate-1-, intermediate-2-, and high-risk patients (by international prognostic scoring system criteria) was 67.2, 27.1, 10.3, and 6.0 months, respectively [5]. The median age of patients with MDS in Korea was reported in two further retrospective analyses of 149 and 227 patients as 53 and 57 years, respectively $[6,7]$. This is younger than the median age of diagnosis in Western patients, measured in the MDS Registry in Düsseldorf as 72 years [8].

Patients with BMFS can suffer symptomatic anemia, which causes patients to present with fatigue, and can adversely affect their health-related quality of life (QoL), and cytopenia, which can be life-threatening. These symptoms can be managed with red blood cell (RBC) transfusions by increasing patients' hemoglobin levels and thus improving their QoL. Although providing essential 
Table 1 Summary of a study in patients with AA or MDS in Korea [13] a Calculated as a percentage of the patients with iron overload $D F O$ deferoxamine

\begin{tabular}{lccc}
\hline$n(\%)$ & AA $(n=795)$ & MDS $(n=333)$ & Total $(n=1,128)$ \\
\hline Patients with iron overload & $200(25)$ & $131(39)$ & $331(29)$ \\
Patients who received DFO $^{\mathrm{a}}$ & $33(17)$ & $14(11)$ & $47(14)$ \\
Patients with organ damage $^{\mathrm{a}}$ & $68(34)$ & $29(22)$ & $97(29)$ \\
Chronic liver disease $^{\mathrm{a}}$ & $41(21)$ & $12(9)$ & $53(16)$ \\
Diabetes mellitus/glucose intolerance $^{\mathrm{a}}$ & $27(14)$ & $14(11)$ & $41(12)$ \\
Cardiac dysfunction $^{\mathrm{a}}$ & $14(7)$ & $2(2)$ & $16(5)$ \\
Gonadal dysfunction $^{\mathrm{a}}$ & $12(6)$ & 0 & $12(4)$ \\
Pituitary dysfunction $^{\mathrm{a}}$ & $10(5)$ & 0 & $10(3)$ \\
Skin pigmentation $^{\mathrm{a}}$ & $10(5)$ & $8(6)$ & $18(5)$ \\
\hline
\end{tabular}

supportive therapy, regular RBC transfusions can, however, lead to iron overload. Humans have no active mechanism for the excretion of excess iron, so patients transfused with 10-20 lifetime transfusions (20-40 RBC units; in Korea, one RBC unit is $400 \mathrm{~mL}$ ) can suffer the consequences of iron overload [9], such as hypertransaminasemia and cirrhosis of the liver, dilated cardiomyopathy, and progressive dysfunction of the endocrine glands [10-12].

This paper will review data highlighting the need to monitor and treat iron-overloaded patients with AA and MDS in Korea, the impact of iron overload on patients receiving hematopoietic stem cell transplantation (HSCT), and the current clinical practices related to the treatment of iron overload.

\section{Iron overload in patients with AA and MDS}

The prevalence of iron overload and organ damage in Korean patients with AA or MDS who have a history of RBC transfusions ( $>20$ units) has been surveyed by the Korean Iron Overload Study Group [13]. By February 2007, data had been collected from a cross-sectional survey in 1,128 adult patients treated at seven university hospitals in Korea (Table 1).

These data show that a substantial proportion $(n=331)$ of patients with AA or MDS in this Korean study suffered from iron overload (serum ferritin $>1,000 \mathrm{ng} / \mathrm{mL}$ ), and all of the patients analyzed who were treated with iron chelation therapy with deferoxamine (DFO; Desferal ${ }^{\circledR}$ ) had organ damage. In these patients, iron chelation treatment had not been actively administered until complications related to iron overload had appeared. Among the 331 patients who were diagnosed with iron overload, 97 also had organ dysfunction. Table 2 summarizes the clinical characteristics of these patients, showing that they were heavily transfused, with a high iron burden (high serum ferritin level) and had long duration of disease [13].

This study by the Korean Iron Overload Study Group also showed that there was a correlation between serum
Table 2 Characteristics of the patients with iron overload and organ dysfunction $(n=97)$ [13]

\begin{tabular}{lll}
\hline & AA $(n=68)$ & MDS $(n=29)$ \\
\hline Age, years (range) & $45(17-78)$ & $58(32-78)$ \\
Male:female & $42: 36$ & $19: 10$ \\
$\begin{array}{l}\text { Severity of AA } \\
\text { Severe, } n(\%)\end{array}$ & $57(83.8)$ & - \\
$\quad$ Moderate, $n(\%)$ & $11(16.2)$ & - \\
$\begin{array}{l}\text { Duration of illness, } \\
\quad \text { years (range) }\end{array}$ & $8.2(0.9-30.0)$ & $3.0(0.5-17.0)$ \\
$\begin{array}{l}\text { Duration of } \\
\text { transfusions, } \\
\quad \text { years (range) }\end{array}$ & $6.0(0.6-24.3)$ & $2.2(0.5-7.0)$ \\
$\begin{array}{l}\text { Duration of } \\
\text { transfusion } \\
\text { dependence, } \\
\quad \text { years (range) }\end{array}$ & $5.0(0-162)$ & \\
$\begin{array}{l}\text { RBC transfusions, } \\
\quad \text { (range) }\end{array}$ & $104(12-350)$ & $70(12-200)$ \\
$\begin{array}{l}\text { Serum ferritin, } \\
\text { ng/mL (range) }\end{array}$ & $4,084(1,254-22,916)$ & $5,344(1,249-20,822)$ \\
\hline
\end{tabular}

ferritin and number of transfusions, duration of transfusion therapy and duration of transfusion dependence (Fig. 1).

In Japan, a large study retrospectively investigating data from 292 patients with MDS and AA found that of 75 deaths, $97 \%$ were in patients who had serum ferritin levels $>1,000 \mathrm{ng} / \mathrm{mL}$ [14]. Another Japanese study in 13 patients with AA also highlighted the dangers of iron overload in transfusion-dependent patients. The patients who had impaired cardiac pump function died of congestive heart failure within 1 year of detecting abnormal findings in their stress-velocity relation. These patients may have benefited from iron chelation therapy to reduce their myocardial iron burden [15].

The effect of iron overload on the survival of patients with MDS has also been studied in a retrospective analysis of 467 patients in Italy. These data indicate that transfusiondependent patients had a decreased overall survival compared with those who were not dependent on transfusions 

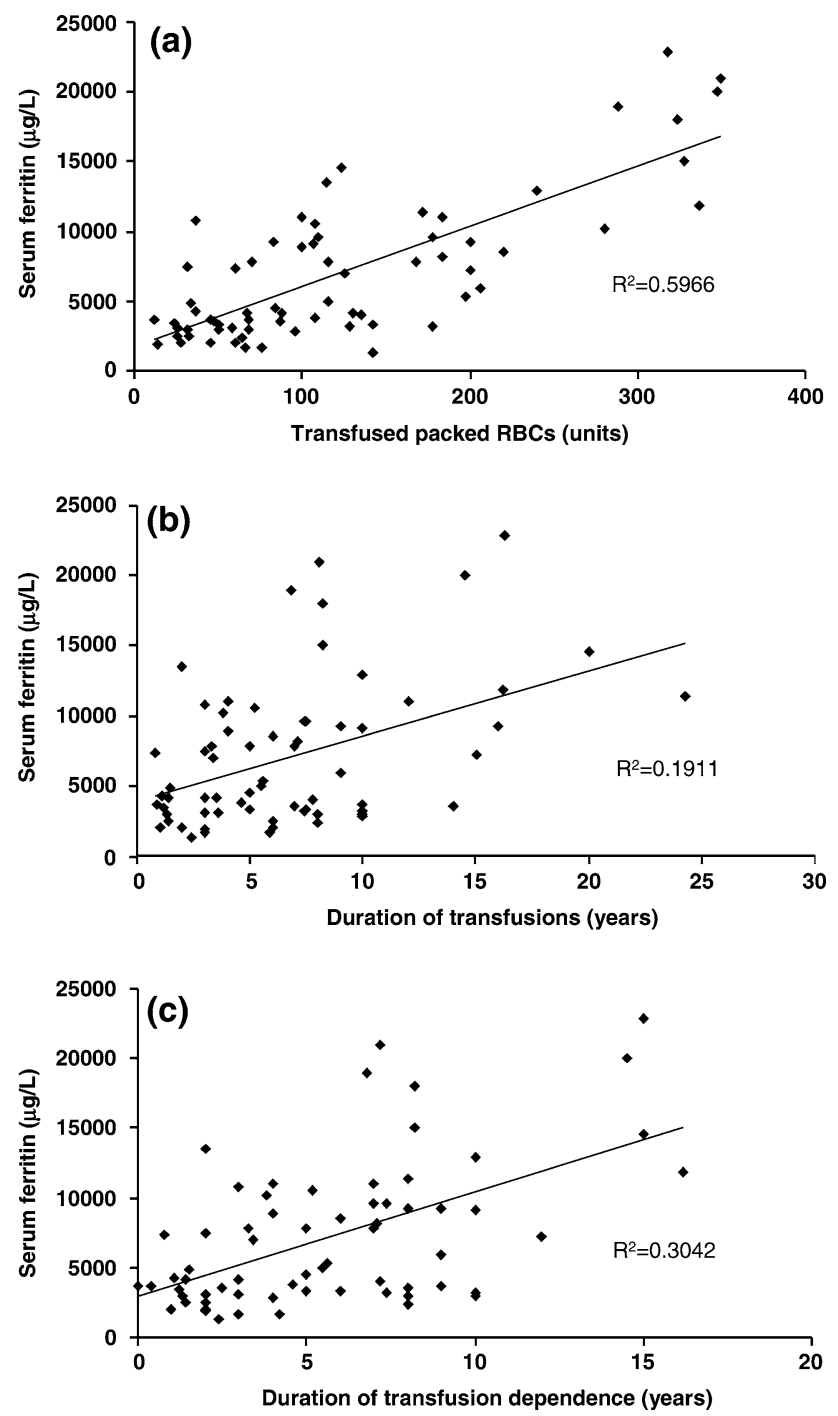

Fig. 1 Correlations between serum ferritin levels and parameters related to RBC transfusions (a number of packed RBC transfusions, $\mathbf{b}$ duration of transfusions, $\mathbf{c}$ duration of transfusion dependence) in iron-overloaded Korean patients with AA and MDS [13]. Reproduced with permission

( $P<0.001$; Fig. 2$)$, and that development of iron overload decreased overall survival $(P=0.003)$ [11]. This study also demonstrated that the negative effect of iron overload on overall survival was more prominent in patients with a good prognosis (median survival $>100$ months) than in those with a poor prognosis (median survival of approximately 50 months) [16].

\section{Iron overload in patients undergoing HSCT}

Patients receiving HSCT for hematologic malignancy or BMFS commonly develop iron overload following intensive supportive transfusion therapy, required following conditioning [17]. Some patients may also have received

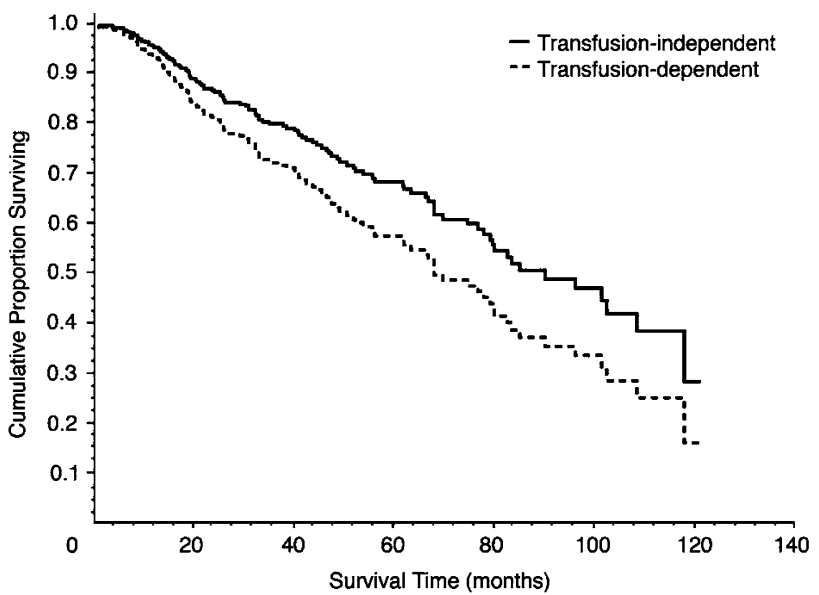

Fig. 2 Kaplan-Meier curve showing overall survival of patients with good-prognosis MDS who were transfusion dependent or independent [11] Reprinted with permission from the American Society of Clinical Oncology. Malcovati L et al. J Clin Oncol. 2005;23:7594-7603.

${ }^{\circ} 2005$ American Society of Clinical Oncology

transfusions as supportive therapy for their BMFS prior to the transplantation procedure. Studies outside of Korea emerging over the last few decades have shown a significant effect of pre-transplant iron overload on survival of sub-groups of patients with BMFS and acute myeloid leukemia (AML) undergoing HSCT [18-20]. A case study in a 29-year-old male Japanese patient with AA undergoing bone marrow transplantation suggested that this patient developed accelerated tissue damage due to iron overload following allogeneic HSCT. The patient received $28 \mathrm{~L}$ of blood prior to transplantation and $8 \mathrm{~L}$ after, and developed iron overload demonstrated by large iron deposits in his liver and stomach biopsies. The authors concluded that the patient developed diabetes mellitus as a result of the secondary iron overload, and that there is a possibility that tissue damage due to the iron deposits may have been accelerated because of the HSCT [21].

In a retrospective analysis of 47 Korean children with severe AA receiving HSCT grafts from human leukocyte antigen-matched siblings, 30 patients had received $<20$ transfused RBC units, and 17 patients $\geq 20$ units. Although progressive rejections were observed in the patients who had received $\geq 20$ transfusions, there was no correlation between transfusion volume and the incidence of graftversus-host disease or survival in these patients. While these results suggest that multiple transfusions may not be a risk factor for rejection or poor outcome, further prospective investigation is needed in larger populations [22].

A US study examining the degree of hepatic iron overload in ten patients who died 50-100 days after receiving HSCT for various hematologic malignancies found strong correlations between bone marrow iron content and hepatic iron index 50-100 days post transplant; 
the hepatic iron index was in the range seen in patients with hereditary hemochromatosis. The authors concluded that an evaluation of tissue iron stores should be included in the routine assessment of all patients after HSCT and that effective phlebotomy or iron chelation therapy should be offered to patients with significant iron overload [17].

\section{Assessment and treatment of iron-overloaded patients with BMFS}

Monitoring body iron levels is essential for identifying patients who are iron overloaded and who may be potential candidates for iron chelation therapy. Once treatment has been initiated, iron levels should continue to be regularly monitored to assess efficacy of iron chelation therapy to maintain iron burden below critical levels. Monitoring of iron levels is also useful to adjust the dose of the iron chelator to achieve the goal of therapy, whether this is maintenance or reduction of iron burden.

\subsection{Assessment of iron overload}

In order to adequately manage iron overload, it is important that body iron levels are assessed on an ongoing basis. There are a range of techniques available to assess iron levels, including measurement of serum ferritin levels, liver iron concentration (LIC) by biopsy, and the use of magnetic resonance imaging (MRI) to measure hepatic and cardiac iron concentrations $[23,24]$. Serum ferritin is the least costly and most convenient and practical of these, and is commonly used in Korea. Levels should be monitored regularly in patients with BMFS who are chronically transfused. Serum ferritin levels $<1,000 \mathrm{ng} / \mathrm{mL}$ are known to be associated with a very low incidence of iron-induced complications, while patients whose levels are $>1,000 \mathrm{ng} /$ $\mathrm{mL}$ can suffer from cardiac, hepatic, and endocrine complications of iron overload [14, 25]. LIC is a good predictor of total body iron, and can be measured by direct biochemical measurement using a needle biopsy; however, it can lead to complications such as bleeding, infection, and hemobilia in patients with MDS [26]. MRI indirectly measures iron content using parameters known as $\mathrm{T} 2 *$ or $\mathrm{R} 2 *$, which are related to the concentration of paramagnetic iron in the organ [26]. A Korean multicenter study on the use of MRI to monitor patients with iron overload is currently ongoing.

\subsection{Practical use of DFO in iron-overloaded patients}

To prevent the life-threatening clinical consequences of iron overload, iron chelation therapy should be initiated in chronically transfused patients when serum ferritin levels reach $>1,000 \mathrm{ng} / \mathrm{mL}[14,27]$. From 1998 until recently, DFO was the only iron chelator available in Korea. In many parts of the world, including Korea, DFO is administered as an intravenous (IV) or subcutaneous (SC) infusion over 8$24 \mathrm{~h}$ per day, 5-7 days/week. In Korea, some patients receive a concomitant DFO injection during their RBC transfusions. In Japan, it is common practice to administer DFO fortnightly rather than nightly, and in some patients as a bolus IV injection. Moreover, most patients in Japan receive treatment on an outpatient basis, and infusion pumps for DFO therapy are not reimbursed [14].

Although published data on the use of iron chelation therapy are mostly from patients with thalassemia, data in patients with BMFS are emerging. Recent reports from Europe and Canada have shown a survival advantage in transfusion-dependent patients with MDS who were adequately chelated compared with those who were not [28, 29]. Other studies have found that DFO may reduce the transfusion requirement of patients with $\operatorname{MDS}[30,31]$, while another study in 11 patients with MDS demonstrated an improvement in erythropoietic output and a reduction in transfusion requirement following DFO treatment [32]. A third study in 12 multiply transfused patients with various BMFS demonstrated induction of urinary iron excretion and reduction in serum ferritin, liver enzyme and liver iron levels [33]. A further study in six of the same patients with elevated myocardial iron showed normalization of myocardial iron, as estimated by MRI R2* measurements after 6-18 months of treatment with DFO [34].

In Korea, chelation therapy is not widely used for the treatment of patients with iron overload. DFO is usually prescribed only to patients with overt secondary hemochromatosis, and is not routinely used for the prevention of hemochromatosis. The cross-sectional survey conducted by the Korean iron overload study group showed that only $18 \%$ of iron-overloaded patients in Korea received iron chelation therapy [13]. Furthermore, iron-overloaded patients with AA are more commonly administered iron chelation therapy than those with MDS. The reluctance to administer iron chelation therapy to patients with MDS in Korea may stem from the advanced age of these patients, and because some patients with poor prognosis may not survive long enough to develop iron overload or to gain benefit from iron chelation therapy. Considerations with administering DFO include the difficulty in obtaining the required infusion pumps and the need for hospitalization. Furthermore, DFO infusions can also have a negative impact on patients' QoL, as the infusions can be troublesome, time-consuming and painful for patients. This can be particularly problematic in older patients as bruising may occur at the infusion site due to decreased platelet counts or platelet dysfunction [35]. 
The most common adverse events (AEs) reported following DFO administration are site soreness/rash, allergic reaction to medication, breathing problems, nausea, tinnitus and joint or muscle pain, headache, hives, nausea, fever, vomiting, and abdominal pain [36, 37]. In countries where DFO is administered as an IV or SC infusion, some of these issues can be addressed to some extent to help increase compliance. For example, the injection site of the therapy can be varied to decrease the likelihood of local skin reactions, butterfly needles can be used, and patients should be properly trained to ensure that SC, rather than intradermal, infusions are achieved; patients should also be educated about the most common AEs that might be expected [38]. Specific AEs in patients with BMFS treated with DFO have been noted. Four cases of development of mucormycosis were reported in Japanese patients with AA treated with DFO, indicating that DFO may be a risk factor for mucormycosis in these patients [39]. Furthermore, a case of ocular toxicity was reported in an 8-yearold patient with AA being treated with DFO in Germany for transfusional iron overload. The ocular toxicity improved following discontinuation of DFO for 3 months [40].

\subsection{Clinical evaluation of deferasirox}

Advances in the understanding of the dangers of iron overload and the availability of alternative iron chelation therapies for the management of iron overload may initiate a change in the treatment strategy for iron-overloaded patients with BMFS in Korea. Deferasirox $\left(\right.$ Exjade $^{\circledR}$; ICL670) is a once-daily, oral iron chelator that was launched in Korea in April 2007 for the treatment of transfusional iron overload in pediatric and adult patients [41], and is also approved in the USA, Europe, and many countries worldwide.

During its clinical evaluation around the world, deferasirox was studied in more than 450 patients with MDS and other BMFS [35]. Baseline data from these trials indicated a high iron burden in transfusion-dependent patients with MDS, DBA, AA, and Fanconi's anemia, suggesting that, despite the prior availability of DFO, these patients had significantly high levels of iron overload [35, 42, 43]. The Catholic University of Korea took part in a 1-year, multicenter study that enrolled patients aged $\geq 2$ years with a range of transfusion-dependent anemias, including MDS. This study demonstrated that patients had a high baseline serum ferritin of $2,755 \mathrm{ng} / \mathrm{mL}$ and LIC of $9.4 \mathrm{mg} \mathrm{Fe} / \mathrm{g}$ dry weight, indicating significant iron burden. For the patients who had previously been chelated, this indicates that their treatment regimen was not providing adequate management of their iron burden, and data clearly indicate a need for chelation therapy in those who were chelation-naïve.
One of the deferasirox core 1-year registration studies in the US included 47 regularly transfused patients with MDS and 30 with DBA, assigned to deferasirox dose groups according to their baseline LIC. This study demonstrated dose-dependent iron excretion in patients with MDS and DBA dosed with deferasirox at 10,20 , and $30 \mathrm{mg} / \mathrm{kg} /$ day (Fig. 3), and a statistically significant mean decrease in LIC of $9.9 \mathrm{mg} \mathrm{Fe} / \mathrm{g} \mathrm{dw}( \pm 5.5 ; P<0.001)$ in patients receiving 20 or $30 \mathrm{mg} / \mathrm{kg} / \mathrm{day}$. The study showed no evidence of differences in the toxicity or tolerability between the patients with MDS and other patients in this trial [35].

In another 3-year prospective deferasirox study in the US enrolling 176 patients with MDS, deferasirox decreased serum ferritin levels from a baseline of $3,398 \pm 3,088$ to $3,065 \pm 1,743, \quad 2,775 \pm 1,355, \quad 2,759 \pm 1,562, \quad$ and $2,603 \pm 1,336 \mathrm{ng} / \mathrm{mL}$ at $3,6,9$, and 12 months, respectively. There was also a sustained suppression of mean labile plasma iron to the normal range after 3 months of treatment, and a hematological improvement in five $(6 \%)$ of the patients, as defined by International Working Group criteria: three patients showed an erythroid response (one major; two minor); two major platelet responses and one major neutrophil response [44].

All these trials have shown that deferasirox is generally well tolerated with a defined safety profile in patients with MDS, as well as other anemias. The most common treatment-related AEs included transient, mild-to-moderate gastrointestinal disturbances and skin rash. No progressive increases in serum creatinine were noted [45]. Treatment with deferasirox should be initiated in patients who have received more than 20 units of RBCs and have a serum ferritin level $>1,000 \mathrm{ng} / \mathrm{mL}$. The recommended initial daily dose of deferasirox is $20 \mathrm{mg} / \mathrm{kg}$ body weight, which

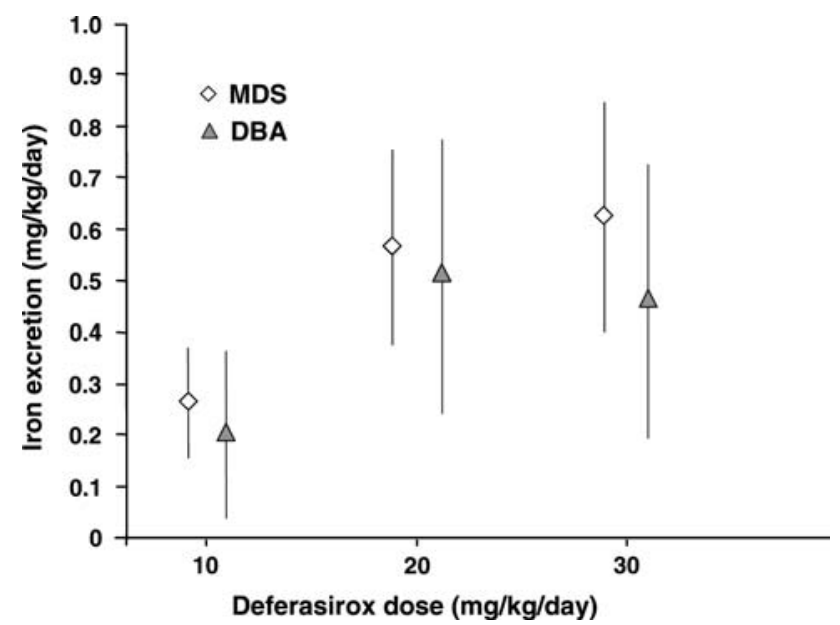

Fig. 3 Changes in iron excretion in patients with MDS and DBA dosed with deferasirox at 10,20 , and $30 \mathrm{mg} / \mathrm{kg} /$ day. Adapted from [35]. Reproduced with permission. Porter J et al. Eur J Haematol. 2008;80:168-176. ${ }^{\odot} 2008$ Blackwell Publishing 
Table 3 Management of diarrhea and skin rash

\begin{tabular}{lc}
\hline When diarrhea occurs & When diarrhea resolves \\
\hline $\begin{array}{l}\text { Primary care } \\
\text { Use an anti-diarrheal therapy (e.g., loperamide) }\end{array}$ & $\begin{array}{c}\text { Reintroduce deferasirox at a lower } \\
\text { dose and gradually escalate }\end{array}$ \\
$\begin{array}{l}\text { If necessary, reduce dose of deferasirox by half (by } 10 \mathrm{mg} / \mathrm{kg}) \\
\text { If diarrhea persists, take deferasirox at night }\end{array}$ & When rash resolves \\
\hline When rash occurs & \\
\hline $\begin{array}{l}\text { Mild to moderate } \\
\text { Rash often resolves spontaneously }\end{array}$ & $\begin{array}{c}\text { Reintroduce deferasirox at } 10 \mathrm{mg} / \mathrm{kg} \\
\text { (half dose) with or without low-dose } \\
\text { weferasirox may be continued } \\
\text { without dose adjustment }\end{array}$ \\
$\begin{array}{l}\text { Severe } \\
\text { Interrupt deferasirox if necessary } \\
\text { Initiate prednisolone }\end{array}$ & \\
\hline
\end{tabular}

can be increased or decreased according to transfusional iron intake, severity of iron overload and the therapeutic goal of the patient, whether to maintain or decrease iron burden [46]. Dose may be adjusted in response to rising serum ferritin levels or emerging AEs. Dose should be increase to $30 \mathrm{mg} / \mathrm{kg}$ when there is a $25 \%$ increase in serum ferritin levels at two consecutive examinations. In the case of AEs, dose should be reduced by $10 \mathrm{mg} / \mathrm{kg}$ if there is a rise in serum creatinine of $>50 \%$ from baseline, especially in patients who are receiving concomitant cyclosporine A. Dose should similarly be reduced in patients who experience dyspepsia, nausea, vomiting, epigastric pain, and diarrhea.

The most common AEs noted from deferasirox administration are mild-to-moderate gastrointestinal disturbances (Table 3). Diarrhea can be treated with loperamide in the first instance; if it is not controlled, dose should be reduced by half. If diarrhea continues to persist, the medication should be taken before bedtime rather than in the morning. After the diarrhea has resolved, the patients may be rechallenged at a lower dose of deferasirox, gradually escalated to a full dose. Mild-to-moderate rash often resolves spontaneously, and deferasirox may be continued without dose adjustment. Severe skin rash can be treated by discontinuing deferasirox and initiating prednisolone. After the rash has resolved, the patients can be rechallenged with a half dose deferasirox, with or without low-dose prednisolone, and gradually escalated to a full dose. AEs in pediatric patients should be managed in the same way as adult patients. In patients undergoing treatment with immunosuppressive therapies, deferasirox can be administered concomitantly alongside cyclosporine A. In those with iron overload who are candidates for HSCT, deferasirox can be administered prior to HSCT to reduce the patients' iron burden.

\section{Conclusions}

Available guidelines from various countries for the treatment of patients with MDS recommend the use of iron chelation therapy to treat the subset of iron-overloaded patients with good prognosis who may benefit from therapy [27, 47-50]. Despite emerging data indicating that transfusion-dependent patients with BMFS, including those receiving HSCT, are at risk of developing iron overload, as well as the associated clinical consequences, DFO is not routinely used for the treatment of secondary hemochromatosis in Korea. As the negative impact of iron overload on the outcome of transplant recipients is understood, intensive treatment of iron overload with deferasirox prior to HSCT may improve survival in patients with AA or MDS.

Deferasirox, a once-daily, oral iron chelator, has recently been introduced in Korea. Worldwide clinical trials in patients with BMFS have demonstrated its efficacy and tolerability in treating these patients. It is hoped that the availability of this convenient, once-daily, oral therapy in Korea will allow a larger number of patients to gain benefit from iron chelation therapy, and improve compliance in patients who might otherwise find the DFO regimen difficult to adhere to.

\section{References}

1. Young NS. Acquired aplastic anemia. Ann Intern Med. 2002;136:534-46.

2. Alessandrino EP, Amadori S, Cazzola M, et al. Myelodysplastic syndromes: recent advances. Haematologica. 2001;86:1124-57.

3. Storb R. Aplastic anemia. J Intraven Nurs. 1997;20:317-22.

4. Jeong DC, Kang IJ, Koo HH, et al. Epidemiology and clinical outcomes in children with aplastic anemia in Korea: retrospective study. Korean J Pediatr Hematol-Oncol. 2004;11:137-52. 
5. Lee HW, Choi JM, Kang SY, et al. Clinical characteristics and prognosis according to the classification of myelodysplastic syndrome. Korean J Med. 2006;70:253-60.

6. Lee JJ, Kim HJ, Chung IJ, et al. Comparisons of prognostic scoring systems for myelodysplastic syndromes: a Korean multicenter study. Leuk Res. 1999;23:425-32.

7. Lee JH, Lee JH, Shin YR, et al. Application of different prognostic scoring systems and comparison of the FAB and WHO classifications in Korean patients with myelodysplastic syndrome. Leukemia. 2003;17:305-13.

8. Germing U, Strupp C, Kundgen A, et al. No increase in agespecific incidence of myelodysplastic syndromes. Haematologica. 2004;89:905-10.

9. Porter JB. Practical management of iron overload. Br J Haematol. 2001;115:239-52.

10. Schafer AI, Cheron RG, Dluhy R, et al. Clinical consequences of acquired transfusional iron overload in adults. N Engl J Med. 1981;304:319-24.

11. Malcovati L, Della Porta MG, Pascutto C, et al. Prognostic factors and life expectancy in myelodysplastic syndromes classified according to WHO criteria: a basis for clinical decision making. J Clin Oncol. 2005;23:7594-603.

12. Jaeger M, Aul C, Sohngen D, Germing U, Schneider W. Secondary hemochromatosis in polytransfused patients with myelodysplastic syndromes. Beitr Infusionsther. 1992;30:464-8.

13. Cho D, Lee J, Sohn S, et al. Transfusion-related iron overload in Korea. Korean J Hematol. 2007;42(Suppl 2):11-2.

14. Takatoku M, Uchiyama T, Okamoto S, et al. Retrospective nationwide survey of Japanese patients with transfusion-dependent MDS and aplastic anemia highlights the negative impact of iron overload on morbidity/mortality. Eur J Haematol. 2007;78: 487-94.

15. Ohnuma K, Toyoda Y, Nishihira H, et al. [Detection of early cardiac dysfunction in patients with transfusion-dependent aplastic anemia and chronic iron overload in childhood. Stressvelocity relation as a sensitive index by echocardiography]. Rinsho Ketsueki. 1996;37:825-32.

16. Malcovati L, la Porta MG, Cazzola M. Predicting survival and leukemic evolution in patients with myelodysplastic syndrome. Haematologica. 2006;91:1588-90.

17. Strasser SI, Kowdley KV, Sale GE, McDonald GB. Iron overload in bone marrow transplant recipients. Bone Marrow Transplant. 1998;22:167-73.

18. Armand P, Kim HT, Cutler CS, et al. Prognostic impact of elevated pretransplantation serum ferritin in patients undergoing myeloablative stem cell transplantation. Blood. 2007;109:4586-8.

19. Altes A, Remacha AF, Sarda P, et al. Early clinical impact of iron overload in stem cell transplantation. A prospective study. Ann Hematol. 2007;86:443-7.

20. Evens AM, Mehta J, Gordon LI. Rust and corrosion in hematopoietic stem cell transplantation: the problem of iron and oxidative stress. Bone Marrow Transplant. 2004;34:561-71.

21. Oguchi T, Kitano K, Kobayashi H, Saito H, Okamoto S, Kiyosawa K. Aplastic anemia complicated with secondary hemochromatosis after allogenic bone marrow transplantation. Rinsho Ketsueki. 1995;36:1188-92.

22. Bin JH, Yoo YK, Kim SY, et al. The effects of multiple transfusion on the outcomes of bone marrow transplantation from HLA-matched sibling donor in patients with severe aplastic anemia. Korean J Pediatr Hematol-Oncol. 2003;10:30-8.

23. Anderson LJ, Holden S, Davis B, et al. Cardiovascular T2-star $(\mathrm{T} 2 *)$ magnetic resonance for the early diagnosis of myocardial iron overload. Eur Heart J. 2001;22:2171-9.

24. St Pierre TG, Clark PR, Chua-anusorn W, et al. Non-invasive measurement and imaging of liver iron concentrations using proton magnetic resonance. Blood. 2005;105:855-61.
25. Olivieri NF, Brittenham GM. Iron-chelating therapy and the treatment of thalassemia. Blood. 1997;89:739-61.

26. Jensen PD. Evaluation of iron overload. $\mathrm{Br} \mathrm{J}$ Haematol. 2004; 124:697-711.

27. Gattermann N. Guidelines on iron chelation therapy in patients with myelodysplastic syndromes and transfusional iron overload. Leuk Res. 2007;31 Suppl 3:S10-5.

28. Leitch HA. Improving clinical outcome in patients with myelodysplastic syndrome and iron overload using iron chelation therapy. Leuk Res. 2007;31 Suppl 3:S7-9.

29. Rose C, Brechignac S, Vassilief D, et al. Positive impact of iron chelation therapy (CT) on survival in regularly transfused MDS patients. A prospective analysis by the GFM. Blood. 2007;110 (11):abst 249.

30. Jensen PD, Jensen IM, Ellegaard J. Desferrioxamine treatment reduces blood transfusion requirements in patients with myelodysplastic syndrome. Br J Haematol. 1992;80:121-4.

31. Del Rio GJ, Fernandez LC, Batlle Fonrodona FJ. Desferrioxamine in the treatment of myelodysplastic syndromes. Haematologica. 1997;82:639-40.

32. Jensen PD, Heickendorff L, Pedersen B, et al. The effect of iron chelation on haemopoiesis in MDS patients with transfusional iron overload. Br J Haematol. 1996;94:288-99.

33. Jensen PD, Jensen FT, Christensen T, Nielsen JL, Ellegaard J. Relationship between hepatocellular injury and transfusional iron overload prior to and during iron chelation with desferrioxamine: a study in adult patients with acquired anemias. Blood. 2003;101:91-6.

34. Jensen PD, Jensen FT, Christensen T, Eiskjaer H, Baandrup U, Nielsen JL. Evaluation of myocardial iron by magnetic resonance imaging during iron chelation therapy with deferrioxamine: indication of close relation between myocardial iron content and chelatable iron pool. Blood. 2003;101:4632-9.

35. Porter J, Galanello R, Saglio G, et al. Relative response of patients with myelodysplastic syndromes and other transfusiondependent anaemias to deferasirox (ICL670): a 1-year prospective study. Eur J Haematol. 2008;80:168-76.

36. Payne K, Desrosiers MP, Proskorovsky I, Ishak K, Baladi JF. Ferritin levels, non-compliance and adverse events in relation to infused iron chelation therapy in an international cohort of patients from actual practice. Haematologica. 2006;91 Suppl 1: abst 1059.

37. Desferal. Basic patient leaflet. Novartis. 1998.

38. Cappellini MD. Overcoming the challenge of patient compliance with iron chelation therapy. Semin Hematol. 2005;42:S19-21.

39. Miyata Y, Kajiguchi T, Saito M, Takeyama H. Development of arterial thrombus of Mucorales hyphae during deferoxamine therapy in a patient with aplastic anemia in transformation to myelodysplastic syndrome. Rinsho Ketsueki. 2000;41:129-34.

40. Spraul CW, Schicketanz C, Lang GE. Ocular side effects of deferoxamine therapy in aplastic anemia with transfusioninduced hemochromatosis. Klin Monatsbl Augenheilkd. 1996;209:31-6.

41. Multinational pharmaceutical firms launch seven new drugs. Pharma Koreana. 2008;17:15.

42. List AF, Esposito J, Decker J, et al. Iron parameters in 84 MDS patients enrolled in a deferasirox (Exjade ${ }^{\circledR}$, ICL670) multicenter trial. Blood. 2006;108(11):abst 4847.

43. Gattermann N, Schmid M, Vassilieff D, et al. Severe iron overload in patients with myelodysplastic syndromes enrolled in a large study of deferasirox (Exjade ${ }^{\circledR}$, ICL670). Leuk Res. 2007;31 Suppl 1:S109-10 (Abstract P129).

44. List AF, Baer MR, Steensma D, et al. Deferasirox (ICL670; Exjade $^{\circledR}$ ) reduces serum ferritin (SF) and labile plasma iron (LPI) in patients with myelodysplastic syndromes (MDS). Blood. 2007;110(11):abst 1470 . 
45. Cappellini MD, Vichinsky E, Galanello R, Piga A, Williamson P, Porter JB. Long-term treatment with deferasirox Exjade $^{\circledR}$, ICL670), a once-daily oral iron chelator, is effective in patients with transfusion-dependent anemias. Blood. 2007;110:abst 2777.

46. Exjade ${ }^{\circledR}$ Swiss PI. http://www.exjade. com/pdf/Exjade_Swiss_ PI_english. pdf (last accessed 30 October 2007). 2005.

47. National Comprehensive Cancer Network. NCCN clinical practice guidelines in oncology-v.1.2008: Myelodysplastic Syndromes. http://www.nccn.org/professionals/physician_gls/pdf/mds. pdf. 2008.
48. Bowen D, Culligan D, Jowitt S, et al. Guidelines for the diagnosis and therapy of adult myelodysplastic syndromes. Br J Haematol. 2003;120:187-200.

49. Alessandrino EP, Amadori S, Barosi G, et al. Evidence- and consensus-based practice guidelines for the therapy of primary myelodysplastic syndromes. A statement from the Italian Society of Hematology. Haematologica. 2002;87:1286-306.

50. Gattermann N, Porter J, Lopes LF, Seymour J. Consensus statement on iron overload in myelodysplastic syndromes. Hematol Oncol Clin North Am. 2005;19 Suppl 1:18-25. 